\title{
PENGARUH YOGA PRANAYAMA TERHADAP NYERI PERSALINAN KALA I FASE AKTIF
}

\author{
Widiastini, Luh Putu ${ }^{1 *}$, Karuniadi, I Gusti Agung Manik ${ }^{2}$ \\ 1,2Program Studi Sarjana Kebidanan dan Profesi Bidan, STIKES Bina Usada Bali \\ *Korespondensi: enick.dilaga@gmail.com
}

\begin{abstract}
Background: Childbirth is a physiological thing where there is a series of processes that end with the release of the conception by the mother. The labor process is identical with the pain that will be experienced. All women who give birth will experience pain during labor and statistically, labor pain cannot be tolerated by two out of three mothers. Purpose: The purpose of this study was to determine the effect of Pranayama Yoga on First Stage Childbirth Pain. Methods: Pre-experimental research design with one group pretest posttest design. This research will be carried out for first-time active mothers in Midwife Independent Practice in November-December 2018. The sample that will be used in this study are all first-phase active mothers in Midwife Independent Practice in November-December 2018. Results: The results of this study are partly Most respondents experienced severe pain before being given Yoga Pranayama as many as 27 people (90\%), and most respondents experienced moderate pain after being given yoga pranayama as many as 16 people $(53.3 \%)$. The results of this study found that there was an influence of Pranayama Yoga on Active Stage I Stage Pain Pain with a value of $\mathrm{p} 0.00$, indicating there was an influence of Pranayama Yoga on Phase I Active Stage Pain in Midwife Independent Practice with a value of $0.00<0.05$. Conclusion: There is a significant effect of Yoga Pranayama on the Pain of the Active Phase I Labor.
\end{abstract}

Keywords: Yoga pranayama; Childbirth pain; First stage of active phase

\begin{abstract}
ABSTRAK
Latar Belakang: Persalinan merupakan hal yang fisiologis dimana terjadi rangkaian proses yang berakhir dengan pengeluaran hasil konsepsi oleh ibu. Proses persalinan identik dengan rasa nyeri yang akan dijalani. Seluruh wanita yang melahirkan akan mengalami nyeri selama proses persalinan dan secara statistik rasa nyeri persalinan tidak dapat ditoleransi oleh dua dari tiga orang ibu bersalin. Tujuan: Tujuan dari penelitian ini untuk mengetahui Pengaruh Yoga Pranayama terhadap Nyeri Persalinan Kala I. Metode: Desain penelitian praeksperimental dengan one group pretest posttest design. Penelitian ini akan dilaksanakan pada Ibu bersalin kala I Fase Aktif di Praktik Mandiri Bidan (PMB) pada bulan November-Desember 2019. Sampel yang akan digunakan pada penelitian ini adalah semua Ibu bersalin kala I Fase Aktif di PMB pada bulan November-Desember 2019. Hasil: Hasil penelitian ini sebagian besar responden mengalami nyeri berats ebelum diberikan Yoga Pranayama yaitu sebanyak 27 orang $(90 \%)$, dan sebagian besar responden mengalami mengalami nyeri sedang setelah diberikan yoga pranayama sebanyak 16 orang $(53,3 \%)$. Hasil penelitian ini mendapatkan hasil bahwa terdapat pengaruh Yoga Pranayama terhadap Nyeri Persalinan Kala I Fase Aktif dengan nilai p 0,00, menunjukan ada pengaruh Yoga Pranayama terhadap Nyeri Persalinan Kala I Fase Aktif di PMB denganp value $0.00<$ 0.05. Simpulan: Terdapat pengaruh yang signifikan Yoga Pranayama terhadap Nyeri Persalinan Kala I Fase Aktif.
\end{abstract}


Kata Kunci: Yoga pranayama; Nyeri persalinan; Kala I fase aktif

\section{PENDAHULUAN}

Kehamilan, persalinan, dan nifas adalah hal yang alamiah yang dialami oleh perempuan dalam kehidupannya. Setiap proses kehamilan, persalinan dan nifas yang dialami oleh wanita dapat menimbulkan perubahan baik fisik maupun psikologis. Perubahan fisik maupun psikologis seringkali membawa permasalahan bagi ibu. Masalah tersebut dapat terjadi mulai dari proses kehamilan sampai saat nifas. Permasalahan yang paling sering timbul adalah ketidaknyamanan dan kecemasan. Kecemasan memiliki hubungan yang signifikan dengan nyeri persalinan (Puspita, 2013).

Persalinan merupakan hal yang fisiologis dimana terjadi rangkaian proses yang berakhir dengan pengeluaran hasil konsepsi oleh ibu . Proses persalinan sendiri terjadi melalui empat tahap persalinan, yaitu kala I, kala II, kala III dan kala IV. Pada kala I persalinan, kontraksi uterus menyebabkan dilatasi serviks dan mendorong janin melalui jalan lahir. Kontraksi uterus pada persalinan menimbulkan rasa nyeri. Nyeri persalinan disebabkan oleh iskemik otot uteri, otot dasar panggul dan perineum. Secara fisiologis nyeri terjadi ketika otot-otot rahim berkontraksi sebagai upaya membuka servik dan mendorong kepala bayi ke arah panggul (Widiastini, 2014).

Faktor-faktor yang memiliki hubungan yang signifikan dengan nyeri persalinan adalah paritas, umur, kecemasan ibu menghadapi persalinan, persepsi (Puspita, 2013). Untuk mengatasi nyeri persalinan dapat dilakukan secara farmakologi maupun nonfarmakologi. Manajemen nyeri secara farmakologi lebih efektif dibanding dengan metode nonfarmakologi namun metode farmakologi lebih mahal, dan berpotensi mempunyai efek yang kurang baik. Sedangkan metode nonfarmakologi bersifat murah, simpel, efektif, dan tanpa efek yang merugikan, akan tetapi penggunaan terapi non farmakologis ini terkendala kebijakan dan peraturan rumah sakit (Almushait \& Ghani, 2014).

Metode non farmakologi dapat meningkatkan kepuasan selama persalinan jika ibu dapat mengontrol perasaan dan ketakutannya. Tehnik relaksasi, teknik pernapasan, pergerakan dan perubahan posisi, massage, hidroterapi, terapi panas/dingin, musik, guided imagery, akupresur, aromaterapi merupakan beberapa teknik nonfarmakologi yang dapat meningkatkan kenyamanan ibu saat bersalin dan mempunyai pengaruh yang efektif terhadap pengalaman persalinan (Behmanesh, Pasha and Zeynalzadeh, 2009). 
Sebanyak $88,6 \%$ ibu menyatakan bahwa keuntungan dari penggunaan metode non farmakologi adalah meningkatkan rasa control diri (Iliadou, 2009). Metode non farmakologis yang saat ini banyak dikembangkan antara lain akupuntur, hypnosis, hydrotheraphy, latihan fisik selama kehamilan, massage dan pijat refleksi, serta yoga (Koyyalamudi et al., 2016).

Yoga prenatal memiliki pengaruh terhadap perubahan kadar endorphin. Yoga prenatal dapat mempercepat proses persalinan, kontraksi uterus menjadi lebih kuat dan meningkatkan kadar hormon endorphin. Hormon endorphin berfungsi agar ibu bersalin menjadi lebih tenang saat merasakan rasa nyeri persalinan (Kartikasari, Hadisaputro, \& Sumarni, 2020). Penelitian sejenis tentang yoga sebelumnya (Wijaya \& Agustini, 2014), mendapatkan hasil bahwa pengaruh yang signifikan yoga pranayama terhadap penurunan tingkat kecemasan pada Ibu hamil Trimester III.

Berdasarkan latar belakang diatas, peneliti tertarik untuk melakukan penelitian untuk mengetahui Pengaruh Yoga Pranayama terhadap Nyeri Persalinan Kala I Fase Aktif di PMB.

\section{TUJUAN}

Tujuan dari penelitian ini untuk mengetahui Pengaruh Yoga Pranayama terhadap Nyeri Persalinan Kala I.

\section{METODE}

Desain penelitian pra eksperimental dengan one group pretest posttest design. Pengukuran nyeri persalinan dilakukan pada satu kelompok. Pengukuran nyeri dilakukan sebelum diberikan yoga pranayama dan setelah diberikan yoga pranayama. Penelitian ini dilaksanakan pada ibu bersalin kala I fase aktif pada bulan November Desember 2019. Sampel yang akan digunakan pada penelitian ini adalah semua ibu bersalin yang berada di PMB pada bulan November-Desember tahun 2019 dengan jumlah 30 responden.

\section{HASIL}

\section{Analisa Univariat}

Pada tabel 1, dapat diketahui bahwa sebagian besar responden berada pada kelompok umur usia reproduksi sehat yaitu sebanyak 21 orang (70\%). Dan paling sedikit berada pada kelompok terlalu tua yaitu sebanyak 4 orang $(13,3 \%)$. 
Tabel 1. Distribusi Responden Berdasarkan Umur

\begin{tabular}{cccc}
\hline No & Kelompok Umur & Frekuensi & Persen (\%) \\
\hline 1 & Terlalu Muda & 5 & 16,7 \\
2 & Usia Reproduksi Sehat & 21 & 70 \\
3 & Terlalu Tua & 4 & 13,3 \\
\hline & Total & 30 & 100 \\
\hline
\end{tabular}

Pada tabel 2 dapat diketahui bahwa sebagian besar responden merupakan multigravida sebanyak 18 orang (60\%). Dan paling sedikit prmigravida yaitu sebanyak 12 orang $(40 \%)$.

Tabel 2. Distribusi Responden Berdasarkan Paritas

\begin{tabular}{cccc}
\hline No & Paritas & Frekuensi & Persen (\%) \\
\hline 1 & Primigravida & 12 & 40 \\
2 & Multigravida & 18 & 60 \\
\hline & Total & 30 & 100 \\
\hline
\end{tabular}

Pada tabel 3 dapat diketahui bahwa sebagian besar responden memiliki tingkat pendidikan SMA sebanyak 21 orang (70\%).

Tabel 3. Distribusi Responden Berdasarkan Tingkat Pendidikan

\begin{tabular}{cccc}
\hline No & Tingkat Pendidikan & Frekuensi & Persen $(\%)$ \\
\hline 1 & SMA & 21 & 70 \\
2 & Perguruan Tinggi & 9 & 30 \\
\hline Total & 30 & 100 \\
\hline
\end{tabular}

Pada tabel 4 dapat diketahui bahwa sebagian besar responden mengalami nyeri berat sebanyak 27 orang $(90 \%)$. Dan paling sedikit mengalami nyeri hebat yaitu sebanyak 1 orang $(3,3 \%)$.

Tabel 4. Distribusi Responden Berdasarkan Tingkat Nyeri Sebelum Pemberian Yoga Pranayama

\begin{tabular}{cccc}
\hline No & Tingkat Nyeri & Frekuensi & Persen $(\%)$ \\
\hline 1 & Sedang & 2 & 6,7 \\
2 & Berat & 27 & 90 \\
3 & Hebat & 1 & 3,3 \\
\hline & Total & 30 & 100 \\
\hline
\end{tabular}

Pada tabel 5 dapat diketahui bahwa sebagian besar responden mengalami nyeri sedang sebanyak 16 orang $(53,3 \%)$. Dan paling sedikit mengalami nyeri ringan yaitu sebanyak 14 orang $(46,7 \%)$. 
Tabel 5. Distribusi Responden Berdasarkan Tingkat Nyeri Setelah Pemberian Yoga

\begin{tabular}{cccc}
\multicolumn{4}{c}{ Pranayama } \\
\hline No & Tingkat Nyeri & Frekuensi & Persen (\%) \\
\hline 1 & Ringan & 14 & 46,7 \\
2 & Sedang & 16 & 53,3 \\
\hline \multicolumn{7}{c}{ Total } & 30 & 100 \\
\hline
\end{tabular}

\section{Analisa Bivariat}

Uji Statistik yang dilakukan untuk mengetahui pengaruh Yoga Pranayama terhadap Nyeri Persalinan Kala I Fase Aktif di PMB PM dilakukan dengan Paired $t$ test perhitungan menggunakan program SPSS 17. Adapun hasil hasil yang diperoleh $p$ value $0.00<0.05$. Hasil penelitian ini menunjukan ada pengaruh Yoga Pranayama terhadap Nyeri Persalinan Kala I Fase Aktif di PMB PM.

Tabel 6. Distribusi Frekuensi Tingkat Nyeri Persalinan Sebelum dan Setelah Diberikan Yoga Pranayama

\begin{tabular}{|c|c|c|c|c|c|c|c|}
\hline \multirow{3}{*}{$\begin{array}{c}\text { Tingkat Nyeri } \\
\text { Sebelum Diberikan } \\
\text { Yoga Pranayama }\end{array}$} & \multicolumn{4}{|c|}{ Setelah Diberikan Yoga Pranayama } & \multirow{2}{*}{\multicolumn{2}{|c|}{ Total }} & \multirow{3}{*}{$\begin{array}{c}p \\
\text { value }\end{array}$} \\
\hline & \multicolumn{2}{|c|}{ Nyeri ringan } & \multicolumn{2}{|c|}{ Nyeri sedang } & & & \\
\hline & $\mathrm{f}$ & $\%$ & $\mathrm{f}$ & $\%$ & $\mathrm{f}$ & $\%$ & \\
\hline Nyeri sedang & 0 & 0 & 2 & 100 & 2 & 100 & 0,00 \\
\hline Nyeri berat & 14 & 51,9 & 13 & 48,1 & 27 & 100 & \\
\hline Nyeri hebat & 0 & 0 & 1 & 100 & 1 & 100 & \\
\hline Total & 14 & 46,7 & 16 & 53,3 & 30 & 100 & \\
\hline
\end{tabular}

Berdasarkan hasil analisis didapatkan bahwa terdapat pengaruh yang signifikan terhadap Nyeri Persalinan Kala I Fase Aktif pada ibu bersalin sebelum dan setelah diberikan Yoga Pranayama dengan nilai p 0,00.

\section{PEMBAHASAN}

Pada hasil penelitian ini didapatkan bahwa Yoga Pranayama memiliki pengaruh yang signifikan terhadap Nyeri Persalinan Kala I Fase Aktif pada ibu bersalin. Hal ini sejalan dengan hasil penelitian sejenisnya sebelumnya pernah dilakukan (Büssing, Ostermann, Lüdtke, \& Michalsen, 2012). Pada penelitian tersebut didapatkan hasil bahwa yoga sebagai intervensi pendukung yang bermanfaat untuk berbagai penyakit yang berhubungan dengan rasa sakit. Individu yang sehat dengan nyeri persalinan, pelaksanaan yoga memiliki efek yang sangat kuat.

Nyeri persalinan unik dan berbeda pada setiap individu karena nyeri tidak hanya dikaitkan dengan kondisi fisik semata, tetapi berkaitan juga dengan kondisi psikologis ibu pada saat persalinan. Kondisi psikologis yang dimaksud adalah rasa takut dan cemas yang berlebihan yang akan menimbulkan atau bahkan memperparah nyeri akibat kondisi fisik. 
Teknik pernapasan yoga dapat menguatkan system pernapasan, menenangkan sistem saraf, membantu mengurangi atau menghilangkan berbagai macam kecanduan dan dapat menguatkan sistem kekebalan tubuh. Pernapasan yoga memainkan peranan penting dalam metabolisme tubuh, yaitu proses tubuh menguraikan nutrisi. Manfaat nyata yang dapat dirasakan dari latihan yoga pranayama ini adalah peningkatan hormone endorphin yang membuat ibu menjadi tenang bahkan saat merasakan nyeri persalinan (Kartikasari et al., 2020).

Mekanisme latihan pernapasan yoga terhadap perubahan fisik yang terjadi pada tubuh diawali dengan terciptanya suasana relaksasi alam sadar yang secara sistematis membimbing pada keadaan relaks yang mendalam. Terciptanya suasana relaksasi akan menghilangkan suara-suara dalam pikiran sehingga tubuh akan mampu untuk melepaskan ketegangan otot. Ketika tubuh mulai santai napas akan menjadi lambat dan dalam, sehingga system pernapasan dapat istirahat. Melambatnya ritme pernapasan ini akan membuat detak jantung menjadi lebih lambat dan memberikan pengaruh positif terhadap keseluruhan sistem sirkulasi dan jantung untuk beristirahat dan mengalami proses peremajaan. Sistem saraf simpatik yang selalu siap beraksi menerima pesan untuk melakukan relaksasi sedangkan sistem saraf parasimpatik akan memberikan respon untuk relaksasi. Selain saraf simpatik, pesan untuk relaksasi juga diterima oleh kelenjar endokrin yang bertanggung jawab terhadap sebagian besar keadaan emosi dan fisik.

\section{SIMPULAN DAN SARAN}

Sebagian besar responden mengalami nyeri berat sebelum diberikan Yoga Pranayama yaitu sebanyak 27 orang (90\%), dan sebagian besar responden mengalami mengalami nyeri sedang setelah diberikan yoga pranayama sebanyak 16 orang $(53,3 \%)$. Hasil penelitian ini mendapatkan hasil bahwa terdapat pengaruh Yoga Pranayama terhadap Nyeri Persalinan Kala I Fase Aktif dengan nilai p 0,00.

Hasil penelitian ini diharapkan dapat digunakan sebagai bahan acuan dan pertimbangan bagi tenaga kesehatan yang memberikan asuhan pada ibu bersalin agar dapat meningkatkan pengetahuan dan keterampilannya dalam memberikan asuhan terutama mengaplikasikan yoga pranayama pada ibu bersalin kala I.

\section{DAFTAR PUSTAKA}

Almushait, M., \& Ghani, R. A. (2014). Perceptiontoward non-pharmacological strategies in relieving labour pain: An analytical descriptive study. J Nat Sci Res, $4(2)$. 
Behmanesh, F., Pasha, H., \& Zeynalzadeh, M. (2009). The effect of heat therapy on labor pain severity and delivery outcome in parturient women.

Büssing, A., Ostermann, T., Lüdtke, R., \& Michalsen, A. (2012). Effects of yoga interventions on pain and pain-associated disability: a meta-analysis. The Journal of Pain, 13(1), 1-9.

Iliadou, M. (2009). Labour pain and pharmacological pain relief practice points. Health Sci J, 3(4), 197-201.

Kartikasari, A., Hadisaputro, S., \& Sumarni, S. (2020). Pengaruh Prenatal Yoga Terhadap Lamanya Persalinan Kala I Kontraksi Uterus Dan Perubahan Kadar Hormon Endorphin Pada Ibu Primigravida Studi Kasus Di Puskesmas Kadugede Kuningan Jawa Barat. Jurnal Ilmu Kesehatan Bhakti Husada: Health Sciences Journal, 11(1), 27-37.

Koyyalamudi, V., Sidhu, G., Cornett, E. M., Nguyen, V., Labrie-Brown, C., Fox, C. J., \& Kaye, A. D. (2016). New labor pain treatment options. Current Pain and Headache Reports, 20(2), 11.

Puspita, A. D. (2013). Analisis Faktor-Faktor yang Mempengaruhi Nyeri Persalinan pada Ibu Bersalin Kala I Fase Aktif di Puskesmas Mergangsang Tahun 2013. STIKES'Aisyiyah Yogyakarta.

Widiastini, L. P. (2014). Buku Ajar Asuhan Kebidanan Pada Ibu Bersalin dan Bayi Baru Lahir. Bogor: In Media.

Wijaya, I. G. N. P., \& Agustini, I. G. A. R. (2014). Pengaruh Yoga Pranayama Terhadap Kecemasan Pada Ibu Hamil Trimester Iii Dalam Menghadapi Persalinan Di Bps Ida Ayu Putu Suartika, Amd. Keb. Jurnal Dunia Kesehatan Volume 3 No 1 Juni 2014, 3(1). 